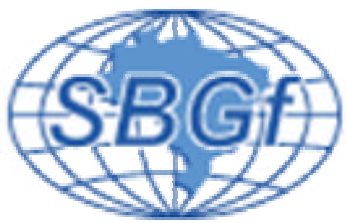

\title{
APLICAÇÃO DA TÉCNICA DE IMAGEAMENTO ELÉTRICO 3D EM ÁREA SOB CONTAMINAÇÃO DE HIDROCARBONETO
}

Marcus Paulus Martins Baessa - Petrobrás/Cenpes, Andresa Oliva e Chang Hung Kiang - Instituto de Geociências e Ciências Exatas - UNESP.

\section{Resumo}

As contaminações por hidrocarbonetos em solo e água subterrânea têm sido alvo de inúmeras pesquisas, principalmente devido à complexidade dos fenômenos químicos e bioquímicos que ocorrem a partir do momento que o contaminante é absorvido pelo solo.

Técnicas diretas tradicionais como sondagens mecânicas e coleta de amostras para análise são comumente utilizadas no mapeamento de plumas de contaminação, mas limitadas devido ao seu custo e morosidade.

Buscando diagnósticos de menor custo e maior agilidade, utilizou-se a técnica de imageamento elétrico 3D na identificação de possíveis plumas de contaminação, em área onde ocorreram vazamentos de hidrocarbonetos em Cubatão (SP).

\section{Introdução}

Um dos problemas de difícil solução nas atividades voltadas para a proteção ambiental é a detecção de áreas contaminadas por hidrocarbonetos derivados de petróleo.

Isto se deve ao fato de que os contaminantes apresentam composição complexa. Além disso, sua interação com o fluxo d'água subterrâneo, com materiais argilosos e com matéria orgânica é bastante complicada do ponto de vista físico-químico.

Organismos capazes de degradar hidrocarbonetos estão presentes em grande número em solos e rochas. Ridgeway et al. (1990) identificou mais de 300 tipos de bactérias que degradam hidrocarbonetos em camadas de sedimentos contaminados. Microorganismos em ambiente aeróbico tendem a reagir mais rapidamente com os hidrocarbonetos do que em anaeróbico. Microorganismos em ambiente anaeróbico utilizam elétrons acessíveis, principalmente nitrato, ferro e sulfato para poderem reagir. Essas reações liberam $\mathrm{CO}_{2}, \mathrm{H}_{2} \mathrm{O}$, calor e ácidos orgânicos (Borden, 1994).

Dentre os produtos liberados nestas reações, os ácidos orgânicos são de grande importância em estudos geofísicos, pois conferem alta condutividade a solos/sedimentos contaminados, depois de determinado período de ocorrência do vazamento.

Os hidrocarbonetos, em sua forma original, apresentam alta resistividade. Estudos como de Gajdos e Kral (1995), realizados em laboratório, mostram que ocorre decréscimo de $20 \%$ da resistividade com a adição de $1 \%$ de óleo bruto ou gasolina em sedimentos arenosos e de $40 \%$ quando se trata de óleo motor.

Deste modo, os métodos geofísicos podem auxiliar consideravelmente em casos de contaminação. Esses métodos vêm sendo utilizados com êxito nestes casos, graças ao baixo custo e a maior agilidade quando comparados aos métodos diretos de investigação.

Para a avaliação de contaminação por hidrocarbonetos, dois métodos têm sido empregados com mais freqüência: o geo-radar e o de eletrorresistividade. En virtude de ruídos indesejáveis que prejudicam os ensaios de radar, quando as antenas de aquisição não são blindadas, os métodos de eletrorresistividade têm sido privilegiados nestes estudos.

Dessa foram, utilizou-se aqui o método da eletrorresistividade, por meio das técnicas de sondagem elétrica vertical (SEV) e imageamento elétrico 3D, para o mapeamento de pluma de contaminação localizada em uma em presa no município de Cubatão (SP).

Dentre as técnicas que se baseiam no método de eletrorresis tividade, a técnica da SEV é a mais utilizada, contemplando investigações verticais de resistividade, ao longo de uma dimensão em profundidade, mas a técnica de imageamento elétrico 3D é considerada mais precisa quando se trata de identificações de anomalias, uma vez que todos estratos geológicos, contaminados ou não, podem ser identificados tridimensionalmente.

\section{Aquisição e Processamento dos Dados}

As técnicas de imagemanto elétrico 3D e as SEVs foram realizadas em uma área localizada no município de Cubatão, com a utilização do equipamento Super Sting $\mathbf{R 8 / I P + 2 8}$. Este equipamento possui sistema multieletrodo (28 eletrodos) (Foto 1 ). 


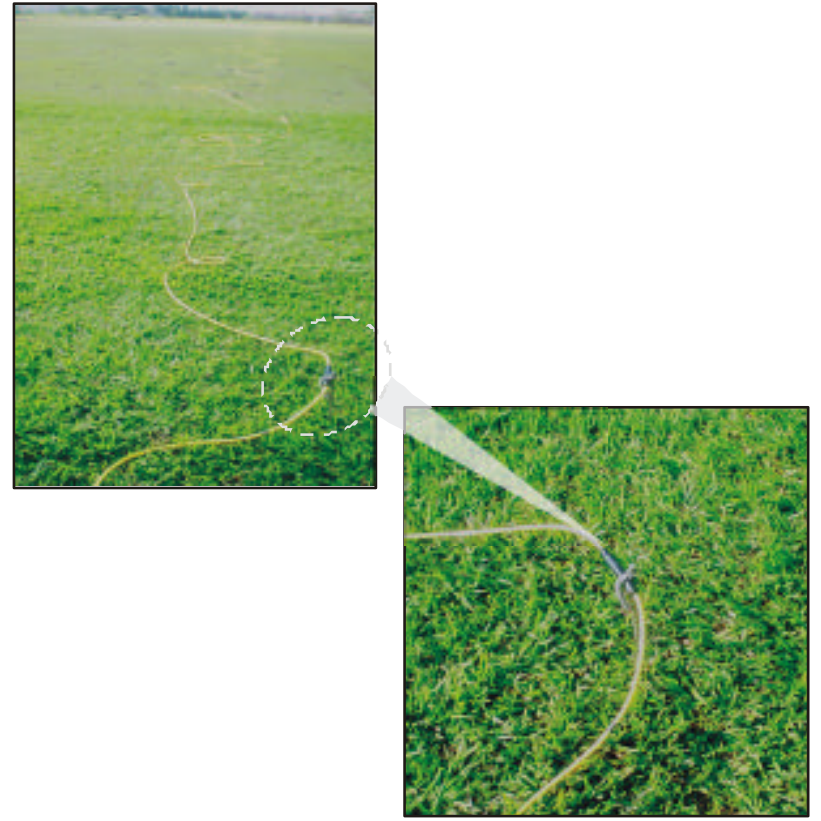

Foto 1 - Sistema multi-eletrodo.

O sistema multi-eletrodo é conectado diretamente ao equipamento ou a uma unidade eletrônica conhecida como switch box. Esse sistema automatizado viabilizou a execução do levantamento 3D, cobrindo uma área de aproximadamente $2100 \mathrm{~m}^{2}$, com aquisição dos dados em cerca de 30 minutos.

Normalmente, o espaço entre os eletrodos no imageamento $3 \mathrm{D}$ é cons tante e determinado a partir do objetivo que a pesquisa almeja. A malha definida neste trabalho foi $4 \times 4 \mathrm{~m}$ (Figura 1), e o arranjo escolhido foi o Dp-Dp.

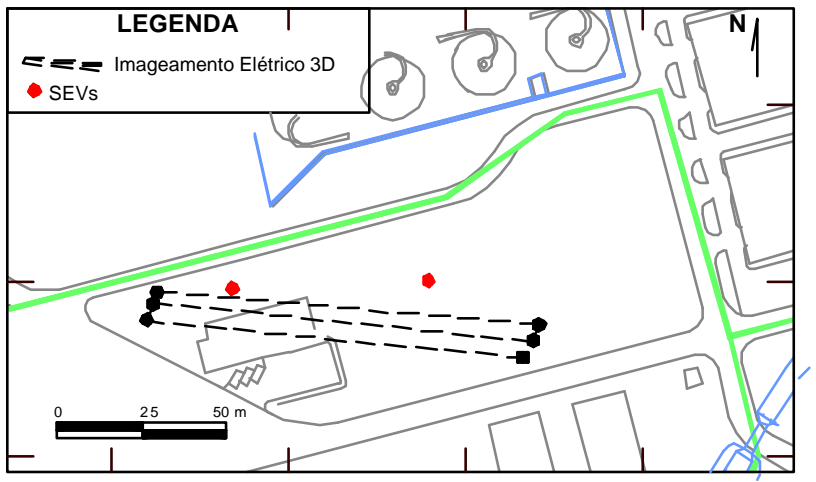

Figura 1 - Localização dos ensaios.

A conversão e a inversão dos dados de resistividade aparente, obtidos em campo, foram realizadas pelo software Earthlmager 3D produzido pela AGI (USA). O método de inversão utilizado foi "smoothness constrained" (Groot-Hedlin e Contable, 1990).
A escolha do método de inversão depende da geologia da área e do objetivo a ser alcançado na pesquisa. Neste trabalho, optou-se pelo método de inversão "smoothness contrained", pois foi o que mais se aproximou dos resultados obtidos nas SEVs interpretadas. Este método de inversão tenta minimizar a diferença entre os valores de resistividade aparente, medidos e calculados, e também minimizar os valores anômalos de resistividade do modelo.

O resultado final é um bloco 3D utilizado nas interpretações geológicas.

\section{Resultados}

A Figura 2 apresenta os resultados do levantamento do imageamento elétrico 3D com os dados processados no programa EarthImager 3D. Esse software permitiu a visualização dos valores de resistividade elétrica em blocos. Nos blocos ainda existe a possibilidade de seccionamento em slices nas direções $\mathrm{X}, \mathrm{Y}$ ou $\mathrm{Z}$.

Devido à ausência de poços na área em questão, a interpretação geofísica permitiu traçar algumas considerações relevantes mas não conclusivas, que auxiliarão na locação de alguns poços de monitoramento.

A profundidade do nível d'água determinada pelas SEVs é de aproximadamente $3,85 \mathrm{~m}$.

Com base no modelo 3D (Figura 2), observa-se à presença de um material bastante condutivo na porção oeste da área, com resistividades inferiores a 40 ohm.m.

Essas anomalias surgem na profundidade aproximadamente de aproximadamente 2,18 m (anomalia maior, extremo oeste) e 4,35 (anomalia menor). O volume total das anomalias é de $1.077,7 \mathrm{~m}^{3}$ (Figura 3). As anomalias seguem em profundidade até aproximadamente $8,7 \mathrm{~m}$.

Este material possivelmente representa contaminação por hidrocarboneto, pois, segundo histórico da área, o vazamento é antigo, propiciando os processos de bioconversão responsáveis pela produção de ácidos orgânicos, redução do $\mathrm{pH}$ e, por conseguinte, aumento da condutividade das fases adsorvidas (zona não saturada) e dissolvida (zona saturada).

Este fato implica em um contraste condutivo em solos/sedimentos resistivos. Esse contraste é mascarado quando os solos/sedimentos são argilosos, pois estes também apresentam baixa resistividade. Nestes casos, os métodos diretos são imprescindíveis para confirmação do material encontrado.

\section{Discussão e Conclusões}

Os resultados obtidos neste trabalho mostram que o método de prospecção geofísica por eletrorresistividade constitui uma ferramenta útil no diagnóstico de possíveis plumas de contaminação por hidrocarbonetos. Entretanto, as técnicas tanto de SEV como de imageamento elétrico 3D mostrar-se-iam mais acuradas 
se associadas a determinados perfis de subsolo (poços de monitoramento).

Independente de dados diretos, o método utilizado foi capaz de sugerir um diagnóstico prévio da área e gerar um planejamento para perfuração de poços de monitoramento para coleta de água e solo.

Com base nestes resultados, sugere-se que a perfuração de poços de monitoramento inicie pela porção oeste, onde foram caracterizadas as anomalias condutivas.

De modo geral, pode-se dizer que o comportamento geoelétrico das contaminações por hidrocarboneto no solo depende do estágio de degradação do hidrocarboneto por microorganismos. Isto mostra que contaminações recentes salientam um contraste resistivo no solo, contrário aos vazamentos antigos.

\section{Agradecimentos}

Os autores agradecem ao Laboratório de Estudo de Bacias (LEBAC) pela cessão do equipamento de geofísica.

\section{Referências}

Borden, R. C., 1994. Handbook of Biorremediation. CRC Press, Boca Raton. 177-199.

Gajdos, V., Kral, V., 1995. Influence of Hydrocarbon Pollution to Soil Conductivity. In: Bell, R. S. (Ed.), Proceedings of the Symposium on the Aplication of Geophysics to Engineering and Environmental Problems, Orlando. 785-789.

Groot- Hedlin, C., Constable, S. 1990. Occam's Inversion to Generate Smooth Two-Dimensional Models from Magnetotelluric Data. Geophysics, 55: 1613-1624.

Ridgeway, H. F., Safarik, J., Phipps, D., Clark, D., 1990. Identification and Catabolic Activity of Well-Derived Gasoline Degrading Bacteria from a Contaminated Aquifer. Applied and Environmental Microbiology, 56: 3565-3575. 


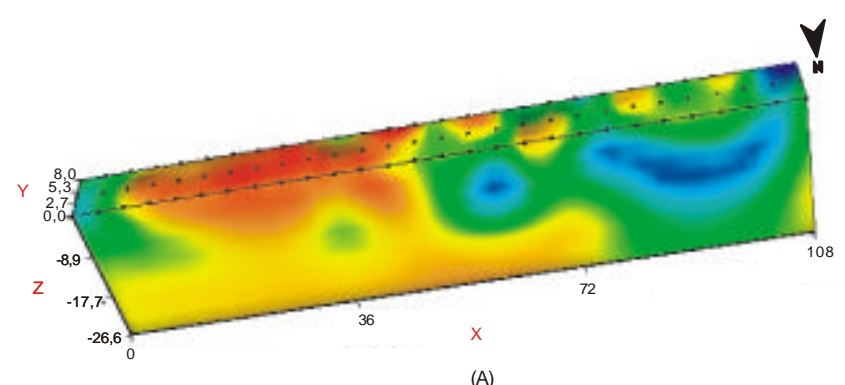

(A)

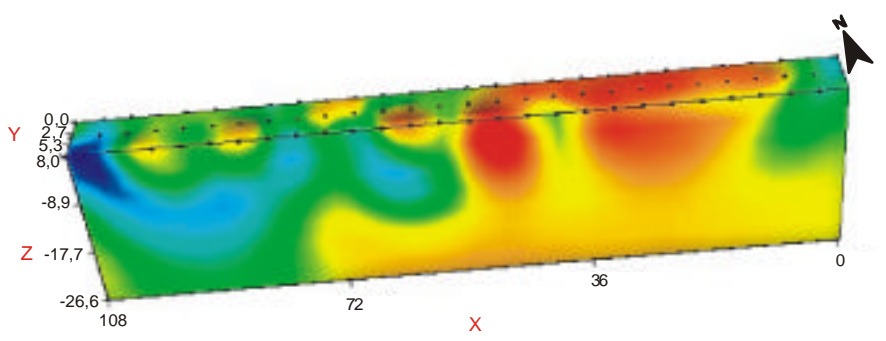

(B)
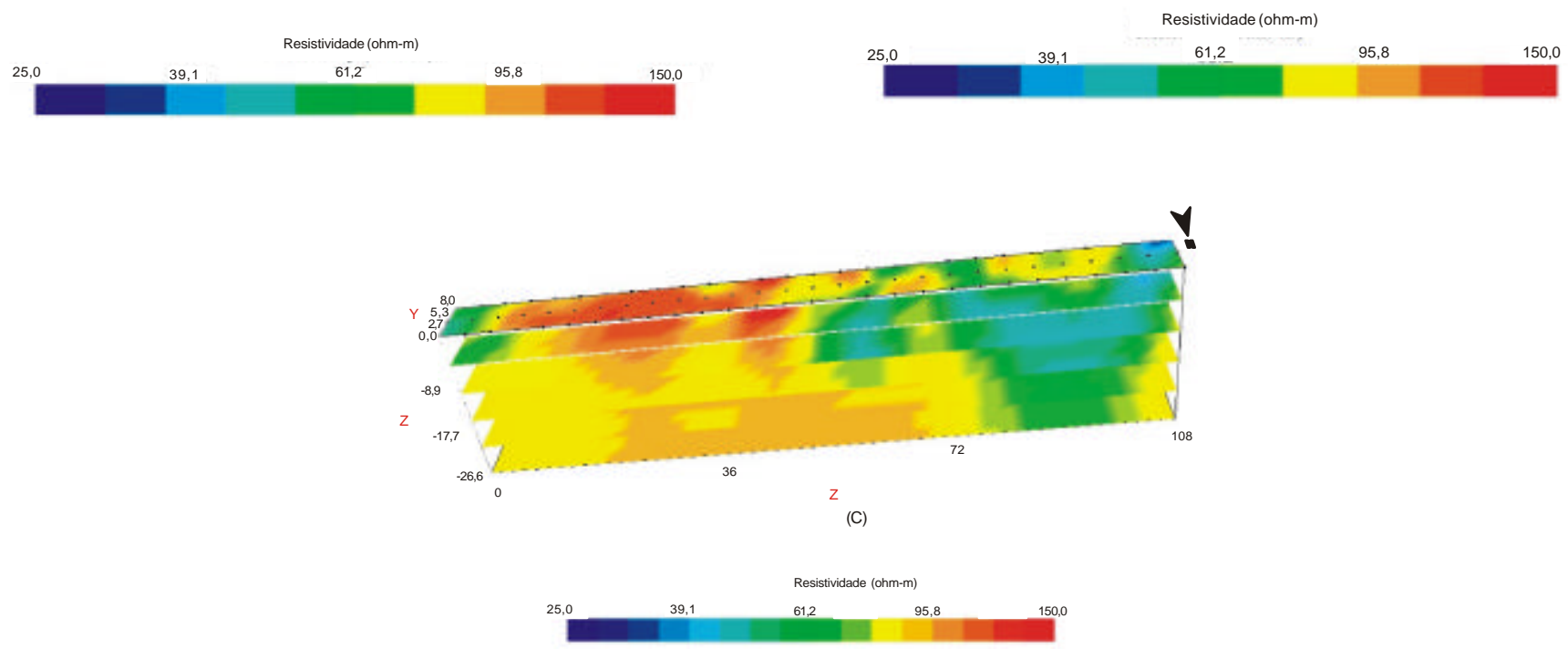

Figura 2 - Modelos de imageamento 3D em imagem frontal (A), detrás (B), seccionamento em slices na direção $Z(C)$.

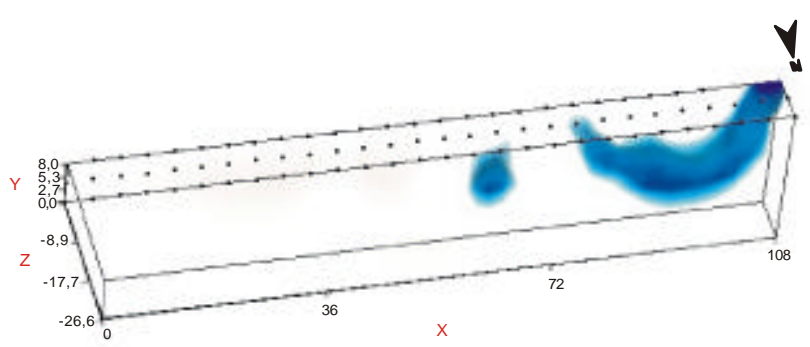

(A)

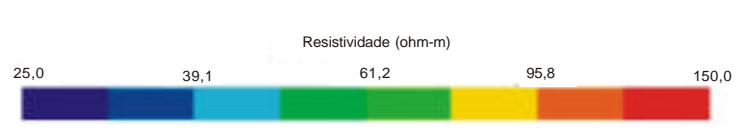

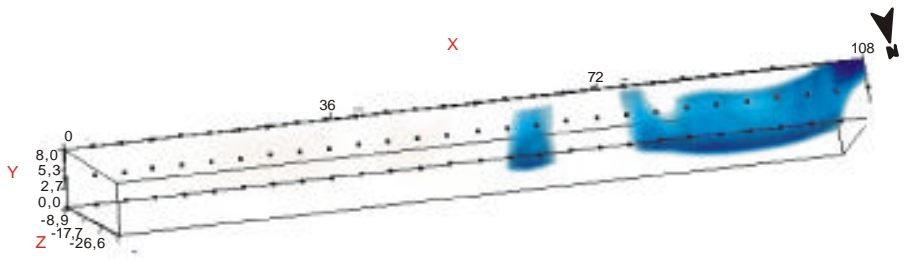

(B)

Figura 3 - Anomalias condutivas identificadas na área de estudo, imagem frontal (a) e aérea (B). 